\title{
AC 2009-1407: TEACHING HISTORICAL PERSPECTIVE USING A TERM PROJECT ON AN INFLUENTIAL STRUCTURAL ENGINEER
}

\section{Matthew Roberts, University of Wisconsin, Platteville}

MATTHEW ROBERTS is an Associate Professor in the Department of Civil and Environmental Engineering. Dr. Roberts earned his B.S. in Civil Engineering from Brigham Young University in 1993 then spent four years in the U.S. Air Force as a civil engineering officer. He received his $\mathrm{Ph} . \mathrm{D}$. from Texas A\&M University in 2002 and has been teaching structural engineering topics at the University of Wisconsin-Platteville since then. 


\title{
Teaching Historical Perspective using a Term Project on an Influential Structural Engineer
}

\begin{abstract}
Details are given on a class project that requires students to prepare a written report and oral presentation on an influential structural engineer. The project includes an extensive peer assessment process completed by the students. The project helps to fulfill the "Contemporary Issues and Historical Perspectives" outcome of the newest version of the Body of Knowledge. The project also seeks to improve student communication skills, thus helping to fulfill the "Communication" outcome. Assessment was conducted to determine the impact of the project in fulfilling these outcomes. Results of the assessment indicate that the project has a significant effect in developing historical perspective by the students. However, assessment results for the communication outcome indicate the project has minimal impact in improving communication skills.
\end{abstract}

\section{Introduction}

Developing a basic understanding of the history of civil engineering is important for undergraduate students. As noted by Petroski, "Engineering history is useful, if not essential, to understanding the nature of engineering."(1) Because of the importance of engineering history for civil engineering students, the newest version of the Body of Knowledge (BOK) includes an outcome on "contemporary issues and historical perspectives." To meet this outcome at the undergraduate level students must be able to "explain the influence of historical ... issues on the identification, formulation, and solution of engineering problems." (2) This paper describes a group term project in which students research and present information about an influential structural engineer. Completion of the project requires the students to explain how historical issues have shaped the civil engineering profession. The learning objectives of the project are:

1. To expose students to a significant structural engineer and help them understand the accomplishments of the engineer and how those accomplishments affected the profession.

2. Improve the students' oral and written communication skills. This learning objective also explicitly helps to fulfill the "communication" outcome of the BOK.

The term project is assigned in a junior-level structural analysis class. In order to implement the project, two lecture periods were lost for student presentations. The project has been assigned each semester since Fall 2005 with many changes and improvements made over the years culminating in the project instructions provided in Appendix A.

This term project was originally adapted from a paper by Thurston. ${ }^{(3)}$ Enhancements made on Thurston's original work will be highlighted in this paper as well as ways in which shortcomings addressed by Thurston have been addressed.

\section{Completing the Project}

The term project starts on the first day of class when students are given detailed instructions on the project and information about the assigning of groups. Groups are assigned 
using the Team-Maker functionality ${ }^{(4)}$ of the Comprehensive Assessment of Team Member Effectiveness (CATME) system. ${ }^{(5)}$ CATME is an online assessment tool that can be used to create student teams and then later to allow students to rate the effectiveness of their team members. In order to use the CATME system, the instructor must first register for an account (registration is free). The instructor then uploads student names in a comma-delimited file that includes an email address for each student. Once the students have been uploaded, the instructor can set up a Team-Maker survey which is completed on-line by the students. The CATME system sends an introductory email to each student with instructions on how to set up a student account and complete the survey. It is helpful to warn the students that the email is coming as it has been the experience of the author that students often perceive the email to be unsolicited ("spam") and delete it immediately. Once students receive the introductory email and set up an account they complete the Team-Maker survey by entering a schedule of times they are available and information about themselves such as gender, grade point average, self-perceived writing ability, sub-discipline within civil engineering, etc. This information is used to make student groups. The results from the Team-Maker survey are used to create groups based on the availability of students to meet outside of class (using their schedule) and optimization of student attributes (such as ensuring that no team has just one female, providing a range of writing skills and sub-disciplines on each team, etc.) The instructor can choose which aspects to include on the survey and how much weight to give each aspect when choosing final teams. The instructor can also set the number of students for each group. The groups are set at three or four students for the assignment detailed in this paper. More specific details on the CATME system, including a review of the pertinent literature, are given by Roberts. ${ }^{(6)}$

Group assignments are made during the first week of class. Once assigned to groups, the students select a famous engineer as the subject. A list of suggested engineers for the project is shown in Figure 1. In an attempt to limit plagiarism, engineers who have been the subject of reports in the last year are removed from the list that is given to the students. Students may choose another subject with instructor approval, but virtually all groups have chosen one of the engineers from the suggested list. The list in Figure 1 was initially adapted from Thurston, ${ }^{(3)}$ but has been significantly added to by the author.

Two weeks after being assigned to groups, students submit an initial proposal about the engineer they have chosen. In the initial proposal the groups give a brief overview of the life of the engineer and list sources they plan to use in writing the report. The requirement to list sources so early in the semester was inspired by the comment made by Thurston that "as deadlines approached, some students reported difficulty in finding appropriate reference material." (3)

Approximately two weeks after submitting the initial proposal, each group submits a second proposal for a visual demonstration to be shown to the class. This visual demonstration will illustrate the subject engineer's contribution to the field of structural engineering. The visual demonstration must be a presentation, experiment, or other visualization explaining a major theoretical or applied contribution of the group's subject to the field of structural engineering. The visual demonstration must clearly illustrate the structural engineering principle. The project instructions are specific as to how the demonstration should illustrate the engineering principle. In order to help the students gain a deeper 
understanding of the engineering principle, the groups must also come up with an example of how the principle would be applied in structural engineering in an application besides the visual demonstration.

\begin{tabular}{ll} 
Daniel Bernoulli (1700-1782) & Stephen P. Timoshenko (1878-1972) \\
Leonhard Euler (1707-1783) & Othmar Ammann (1879-1965) \\
Thomas Telford (1757-1834) & Eugene Freyssinet (1879-1962) \\
John Rennie (1761-1821) & Hardy Cross (1885-1959) \\
Benoit Clapeyron (1799-1864) & Franz Dischinger (1887-1953) \\
Robert Stephenson (1803-1859) & David Steinman (1887-1960) \\
I. K. Brunel (1806-1859) & Pier Luigi Nervi (1891-1979) \\
John Augustus Roebling (1806-1869) & Ulrich Finsterwalder (b. 1897) \\
Horace King (1807-1885) & Eduardo Torroja (1899-1961) \\
Wendel Bollman (1814-1884) & Anton Tedesko (1903-1994) \\
James Buchanan Eads (1820-1889) & Mario Salvadori (1907-1997) \\
Carl Culmann (1821-1881) & Eero Saarinen (1910-1961) \\
Gustave Eiffel (1832-1923) & Nathan M. Newmark (1910-1981) \\
William Jenney (1832-1907) & Felix Candela (1910-1997) \\
Theodore Cooper (1839-1919) & Tung-Yen “T.Y." Lin (1912-2003) \\
Benjamin Baker (1840-1907) & Henry J. Degenkolb (1913-1989) \\
Francois Hennebique (1843-1921) & Egor Popov (1913-2001) \\
Wilhelm Ritter (1847-1906) & Jack R. Janney (b. 1924) \\
Gustav Lindenthal (1850-1935) & Hannskarl Bandel (1925-1993) \\
John Wellborn Root (1850-1891) & Jean M. Muller (1925-2005) \\
Antonio Gaudi (1852-1926) & Heinz Isler (b. 1926) \\
Louis Sullivan (1856-1924) & Christian Menn (b. 1927) \\
Joseph Strauss (1870-1938) & Leslie E. Robertson (b. 1928) \\
Richard "Bucky" Fuller (1895-1983) & Horst Berger (b. 1928) \\
Otto Christian Mohr (1835-1918) & Fazlur R. Khan (1929-1982) \\
Carlo Castigliano (1847-1884) & Eugene C. Figg (1936-2002) \\
Friedrich Engesser (1848-1931) & Charles H. Thornton (b. 1940) \\
Robert Maillart (1872-1940) & Ray W. Clough (b. 1920) \\
\hline
\end{tabular}

Figure 1 - Suggested famous structural engineers

Thurston $^{(3)}$ notes that only a small percentage of groups presented a satisfactory visual demonstration. In order to increase the number of groups that satisfactorily fulfill the demonstration requirements, students are shown a PowerPoint ${ }^{(7)}$ presentation of past visual demonstrations with examples of excellent and sub-par demonstrations. This presentation is shown to the students during the first week of class with the intent of giving the students a better understanding of the expected level of quality. The intent of this presentation is to give them a general idea of what makes a good visual demonstration. There is not enough detail given about previous visual demonstrations to allow the students to duplicate the work of previous students in the class.

Final report drafts are due two months into the semester. This is typically three or four weeks after the second proposal is turned in. The report is called a "draft" because further editing will be required, but the students are instructed that this final report draft is expected to be of excellent quality and represent their best effort. To emphasize the quality expected, a large portion $(40 \%)$ of the total project grade is based on the draft. A 
guideline entitled "Effective Engineering Writing," which was adapted from Parker, ${ }^{(8)}$ is given to the students (and included as Appendix E).

The students turn in one copy of the draft report for the instructor, with all group members identified. Each group also turns in additional anonymous copies with no identification of group members. These anonymous copies are randomly distributed to other members of the class who have one week to perform a peer evaluation of the draft. More details on the peer evaluation are given in the "Peer Assessment" section below. The grade on the final draft is determined using the student peer assessments and a grading rubric used by the instructor (see Appendix D).

In addition to turning in a written draft, the students must also update the Wikipedia ${ }^{(9)}$ entry for their subject engineer. The update to Wikipedia is expected to be non-trivial. The students are required to add at least four sentences to the article on their subject engineer with information on two separate topics. This requirement was added because there was a large discrepancy in the quality of modifications made by students to Wikipedia- some groups were making mostly cosmetic changes (such as grammar) while other groups were adding significant editorial content, or creating completely new entries. In addition to adding content to the Wikipedia article, the students must add at least one reference (web page link or source attribution) to the Wikipedia entry. This requirement to add a reference is in response to the need for better source attribution and scholarly standards in Wikipedia. The Wikipedia part of the project may not be sustainable. Eventually the entries for the engineers will be essentially complete making it difficult for students to make significant additions. However, at the current time students have not had difficulty in making meaningful additions to Wikipedia.

Shortly after the report peer evaluations are completed, the students give group presentations to the rest of the class. The presentation covers the life of the engineer, and also requires students to explain how the engineer advanced the practice of civil engineering. During the presentation the students give their visual demonstration.

The final reports are turned in approximately three weeks after the peer evaluations of the draft are completed. The final report is submitted with all peer evaluation material and the instructor evaluation of the draft report. Grading of the final submissions mainly consists of verifying that the groups used the feedback on the draft report (from both the peer reviewers and the instructor) to improve the paper.

The report and presentation count as $15 \%$ of the total grade in the course. This is a fairly substantial portion of the grade, but the author feels that assigning such a high percentage is necessary to motivate the students to give their best effort.

\section{Peer Assessment}

Peer assessment is an integral part of the project. The students help to assess their fellow students and, more importantly, help to improve writing and teamwork skills both for their peers and themselves. It is important that the need for peer review be adequately communicated to the students. Peer review is an important aspect in the work of practicing engineers and knowing this can motivate the students to take the peer assessment more seriously. ${ }^{(10)}$ 
As part of the project, there are three distinct phases for peer assessment: evaluation of the draft report, evaluation of the presentations, and evaluation of individual member contribution to group success. Student peer evaluation of the reports is accomplished by marking up the draft report and completing an evaluation form (included as Appendix B). Importantly, the form asks for qualitative assessment of the report. For example, instead of simply asking whether the report addresses the required content or asking for a numeric grade (as was done in initial versions of the instrument), the form asks the reviewer to specifically identify the answers to questions that the report should address. The reviewer is required to indicate how the paper could be improved and identify strengths of the paper. In addition, the reviewer must specifically identify ways in which the paper could be improved using the "Effective Engineering Writing" document, requiring each student to at least peruse the writing suggestions.

Peer assessment of the presentations is accomplished using an evaluation form that the students fill out during the presentations. Each student assesses two other group presentations. The typical group size is four students, meaning that each group will have their presentation assessed by eight other students. Like the peer evaluation instrument for the written report, the assessment instrument for the oral presentations is qualitative in nature, asking the students to identify required information in the presentation. A copy of the instrument is included as Appendix C.

For peer assessment of the report and presentations, students are graded based on the effectiveness of their feedback in helping to improve the final report of the group being assessed. This assessment score amounts to $10 \%$ of each student's final grade on the project.

Lastly, peer assessment is used to determine each student's effectiveness as members of his or her team. This assessment is done using the CATME (Behaviorally Anchored Rating Scales) BARS instrument. ${ }^{(5)}$ The CATME BARS measures student performance in five distinct aspects of team member effectiveness:

- Contributing to the team's work,

- Interacting with teammates,

- Keeping the team on track,

- Expecting quality,

- Having related knowledge, skills, and abilities.

The CATME BARS assessment is completed four times during the semester. The first assessment is accomplished after the groups have turned in their second proposal (for the visual demonstration). This assessment is carried out to familiarize the students with the system and help them understand what will be expected of them. The second assessment occurs after turning in the final draft report, the third assessment occurs after the group presentations, and the last assessment is done when the final report is turned in. The results from the CATME BARS assessment is used to adjust student scores on the project (both up and down) based on individual contribution to the team effort. 


\section{Fulfilling the Body of Knowledge}

The assignment detailed in this paper helps students to accomplish several aspects of the body of knowledge. The main learning objective of the assignment helps to further the attainment of the "Contemporary Issues and Historical Perspectives" outcome from the $\mathrm{BOK}$, but the project also aides in the development of the "Communication" outcome.

Specifically, the project develops historical perspective in the students by requiring them to consider several historical issues as they affected the career of their subject engineer. Each report must address the following:

1. Discuss the technological context of the historical period in which your subject lived and worked. What constituted standard engineering practice of the day? What construction techniques and analytical methods were employed? What construction materials were available? How did this affect the work of your subject?

2. Discuss the socioeconomic and political environments of the day as they relate to your subject's work. What challenges, obstacles, or opportunities did these environments afford?

3. Discuss the education and/or practical training of the subject. How would these compare with those of his contemporary engineers? Discuss your own education in this context.

4. Discuss the personal characteristics of the subject. What were his hobbies, interests, or avocations? Of what importance were these outside activities to the subject's work? What role do such activities play in your current educational environment, or what role do you think such activities will play in your professional engineering life?

In addition to developing historical perspective, the project presents students with an opportunity to practice their written and oral communication skills. The peer assessment is particularly important, because it provides the students with feedback on how to improve their writing and also identifies strengths they already possess. Significantly, it is hoped that assessing others' writing forces the students to contemplate the attributes of excellent writing and leads to improvements in their own writing.

\section{Assessment of the Project Effectiveness}

In order to assess the impact of the project, graduating students in the capstone design course were surveyed and asked to name an influential engineer and his/her impact on the profession. The same survey was given to sophomore engineering students (who had not yet taken the course in which the term project is completed) in order to compare before and after knowledge of significant engineers. The assessment form is shown in Figure 2.

For the senior students, $82 \%$ of the students who had completed the project could name a civil engineer who made a significant impact on the profession and explain the impact. Of those students who identified a significant engineer, 56\% identified Karl Terzaghi, the influential geotechnical engineer, $38 \%$ identified a structural engineer, and the remainder identified engineers in other sub-disciplines. The high percentage of students identifying Karl Terzaghi was a significant source of confounding in the survey, making it difficult to assess the full impact of the project. Karl Terzaghi is repeatedly mentioned in the in- 
troductory geotechnical course at this institution (including his picture on the cover of the course pack materials), which explains the relatively high percentage of students identifying him. Only $2 \%$ of sophomore students could identify a significant civil engineer. Comparing assessment results for students before and after completing the project, it appears evident that the project does indeed improve the ability of students to identify a significant engineer and explain his/her contributions.

1. Name a civil or environmental engineer who had a significant impact on the profession. If you cannot think of one, write "none."

2. How did this engineer impact the profession?

3. What is your major (circle one)?

\section{Civil Engineering Environmental Engineering Both}

Figure 2 - Project assessment form

It would also be meaningful to compare seniors who had completed the project with those who had not (the latter forming a control group). Question 3 on the assessment form (see Figure 2) was intended to allow this comparison to be made because students majoring in environmental engineering do not take the course in which the project is completed. However, there are significantly fewer environmental engineering majors than civil engineering majors making it difficult to draw meaningful conclusions. In addition, the environmental engineering students do take the introductory geotechnical engineering course where the accomplishments of Karl Terzaghi are emphasized (he was mentioned by many of them).

In assessing the effectiveness of the project in improving the writing skills of the students a survey item was added for two successive semesters to the end-of-term student evaluations of the course and instructor. Fifty-two students responded. The item stated, "The term project on the famous structural engineer significantly improved my writing skills." The students indicated their agreement with the statement using a five-point Likert scale (with percentages of student responses for each):
1. Strongly Disagree ( $0 \%)$
2. Disagree (35\%)
3. No Opinion $\quad(37 \%)$
4. Agree (27\%)
5. Strongly Agree $\quad(2 \%)$ 
The weighted average of the scores (with 5=Strongly Agree, 4=Agree, etc.) was 2.96 . With 3.00 representing a neutral opinion and values above 3.00 indicating agreement with the statement, it is apparent that the students did not feel the project significantly improved their writing skills.

It is surprising (and somewhat disappointing) to find that the students in general do not perceive that the project significantly improves their writing skills considering the scale of the project and instructor effort. There are several possible explanations for this finding:

1. Because the assessment is an indirect measure-measuring the students' perception of the effectiveness of the project—it may be that a more direct measure would find improvement of student writing skills.

2. One or two students in each team could be doing most of the work so that the other group members would not feel that their writing skills improved. It is hard to defend this hypothesis, however, because the peer assessments performed by the students using the CATME system in general have not shown a large discrepancy in workload between group members.

3. The meaning of "significant" could be skewing the results. That is, some students might agree that the project improves their writing, but not to a significant extent. In order to determine if this was a factor, an additional item was added to the endof-term student evaluation survey: "The term project did not improve my writing skills." The item was expressed in the negative in an attempt to avoid answer patterns. The students were warned before taking the survey that some of the questions were worded negatively like this one. Thirty-two students completed this item on the evaluation. Using the same five-point Likert scale the results were:

$\begin{array}{ll}\text { Strongly Disagree } & (3 \%) \\ \text { Disagree } & (25 \%) \\ \text { No Opinion } & (28 \%) \\ \text { Agree } & (41 \%) \\ \text { Strongly Agree } & (3 \%)\end{array}$

The weighted average of the scores was 3.16 with 3.00 representing a neutral opinion and an average below 3.00 indicating the students agreed that the project improved their writing. Based on these results, it is difficult to justify the hypothesis that the word "significant" biased the results.

Though not directly related to the learning objectives of the project, the students were also asked on the end-of-term evaluations if "the term project was interesting." Thirtythree students responded. Using the same 5-point Likert scale, the results were:

1. Strongly Disagree ( 6\%)

2. Disagree (3\%)

3. No Opinion $(36 \%)$

4. Agree $(48 \%)$

5. Strongly Agree (6\%) 
The weighted average of the scores (with 5=Strongly Agree, 4=Agree, etc.) was 3.46. With 3.00 representing a neutral opinion and values above 3.00 indicating agreement that "the project was interesting," it appears the students were engaged with the project and found it enjoyable.

\section{Future Work}

While the author believes the project is a significant learning experience, there are several changes the author intends to make with the goal of better attaining the learning objectives.

1. A "writing lab" will be added to give the students more guidance in peer assessment of others' papers. The students will each be given a paper to review and the students with the same paper will meet in groups during the lab to discuss the strengths and weaknesses of the paper. The main disadvantage to the writing lab is a lecture period will be lost.

2. The oral presentation will be dropped. By concentrating more fully on the written communication skills, it is hoped that more significant improvements in the students' skills can be achieved. This has the added advantage of recovering two lecture periods.

3. In a further attempt to improve the students' writing skills, cooperation of a faculty member with expertise in teaching writing (e.g., in the English department) will be sought. A campus grant will be applied for in order to get release time for the faculty member to help with the writing lab.

4. In order to prevent plagiarism, software will be used to compare submissions each semester to previous submissions. The author has required students to electronically submit reports in order to build a database of previous submissions to be used in detecting plagiarism.

\section{Differences from the Original Published Work}

There are several additions and enhancements that the author has added to this project compared to the original work by Thurston: ${ }^{(3)}$

- Group reports are submitted by student groups rather than individual essays. In the first semester that the reports were done, individual students submitted essays. However, in a class of 40 students, this required an enormous amount of work on the part of the instructor. Group reports were chosen to reduce the load on the instructor. A lower number of reports also lead to more student peer assessments for each report. More reports (by individuals) also makes it more difficult to check for plagiarism.

- The entire peer assessment process is an enhancement of Thurston's work. The peer assessment of writing was made to address one of the shortcomings indicated in the original work: "The quality of the individual essays was disappointing ... [they] appeared to have been hastily written."(3) By requiring peer assessment of the reports, student writing has improved. Most notably, the resulting papers are generally free of spelling mistakes and grammatical errors, allowing the instructor to focus on more comprehensive improvements to the students' writing. 
- Peer assessment instruments were developed and the CATME Team-Maker and BARS instruments were used to form groups and provide peer assessment.

- The proposals were added to the project based on comments by Thurston concerning difficulties the students had completing the project on time. The first proposal, where the students indicate the intended subject of their reports, was added in order to encourage the students to get started on their research early. The second proposal, concerning the visual demonstrations, follows closely from Thurston's recommendation that the students get written permission for the visual demonstrations in order to ensure that proper demonstrations are performed.

- In writing the reports, the fourth question was eliminated from Thurston's essay topics. This question asked:

"What influences shaped the subject's view of his work? Who were his mentors and role models? What were his political and religious views? Compare and discuss those people or factors that influenced your decision to enter the field of civil engineering, or that currently influence your view of the field.",(3)

This question was dropped from the report requirements because it proved to be difficult for the students to research.

- The addition of the requirement to add a Wikipedia entry.

\section{Conclusions}

The term project described in this paper is an effective way to develop the "historical perspective" outcome of the newest civil engineering BOK. The project requires the students to complete extensive research on an influential structural engineer, write a report about his or her life, and make a short demonstration to the class about the engineer that includes a visual demonstration illustrating the subject engineer's contribution to the field of structural engineering. Student peer assessment of the written report provides valuable feedback to students on ways to improve their writing and helps to identify their strengths. As a result of the requirements of the project, the BOK outcome of "communication" is also addressed by the project. Assessment data show that the project does significantly impact the students when comparing knowledge of influential civil engineers before and after completing the project. However, there seems to be minimal evidence that the project significantly improves student writing skills.

\section{References}

1. Petroski, Henry J. The Importance of Engineering History. Proceedings of the Third National Congress on Civil Engineering History and Heritage Houston. 2001.

2. Body of Knowledge Committee of the Committee on Academic Prerequisites for Professional Practice. Civil Engineering Body of Knowledge for the 21st Century: Preparing the Civil Engineer for the Future. Reston, VA : American Society of Civil Engineers, 2008.

3. Thurston, Howard M. Influential Structural Engineers: A Project in a Third-year Structural Analysis Course. Journal of Engineering Education. 1994, Vol. 83, 2, pp. 156-160. 
4. Layton, Richard, Ohland, Matthew and Pomeranz, Hal R. Software for Student Team Formation and Peer Evaluation: CATME Incorporates Team-Maker. Proceedings of the 2007 ASEE Annual Conference. 2007.

5. Ohland, Matthew W., et al. Developing a Peer Evaluation Instrument that is Simple, Reliable, and Valid. Proceedings of the 2005 ASEE Annual Conference. 2005.

6. Roberts, Matthew W. Using CATME to Create Student Teams and to Evaluate Team-Member Effectiveness. Proceedings of the 2008 ASEE North Midwest Section Conference (CD-ROM). 2008.

7. Microsoft Corporation. Microsoft Office PowerPoint. 2007. Computer Presentation Software.

8. Parker, Philip J. Effective Engineering Writing. Unpublished Student Handout.

9. Wikimedia Foundation, Inc. Wikipedia. [Online] http://www.wikipedia.com/.

10. Hamilton, Scott, et al. Peer Review in Engineering Courses as a Learning Tool. Proceedings of the 2006 ASEE Annual Conference. 2006.

11. National Research Council. How People Learn: Brain, Mind, Experience, and School. Washington, DC : National Academy Press, 2000. 


\section{Appendix A: Famous Structural Engineer Project Instructions}

CEE 3100 - Structural Mechanics - Fall

\section{Overview}

The term project for the semester is a presentation and report on the life and accomplishments of a famous structural engineer. You will be working in groups of three or four to complete the project. There are several parts of this project with due dates as listed below.

$\begin{array}{ll}\text { Groups Assigned } & \text { Monday, September 8 } \\ \text { Subject Proposal } & \text { Monday, September 15 } \\ \text { Demonstration Proposal } & \text { Monday, October 6 } \\ \text { Report Rough Draft } & \text { Thursday, October 16 } \\ \text { Report Final Draft } & \text { Friday, October 31 } \\ \text { Peer Critique } & \text { Friday, November 7 } \\ \text { Final Group Report } & \text { Friday, November 28 } \\ \text { Group Presentations } & \text { Thursday, November 13 } \\ \text { Extra Credit } & \text { Friday, December 12 (Optional) }\end{array}$

\section{Famous Structural Engineers}

Below are listed some famous structural engineers that you might consider using as the subject of your report. If you choose to research an engineer not on the list, talk to me before proceeding.

Daniel Bernoulli (1700-1782)

John Rennie (1761-1821)

Benoit Paul Emile Clapeyron (1799-1864)

I. K. Brunel (1806-1859)

John Augustus Roebling (1806-1869)

Wendel Bollman (1814-1884)

James Buchanan Eads (1820-1889)

Carl Culmann (1821-1881)

Thomas C. Clarke (1827-1901)

Benjamin Baker (1840-1907)

Francois Hennebique (1843-1921)

Wilhelm Ritter (1847-1906)

John Wellborn Root (1850-1891)

Antonio Gaudi (1852-1926)

Joseph Strauss (1870-1938)

Carlo Alberto Pio Castigliano (1847-1884)

Friedrich Engesser (1848-1931)

Stephen P. Timoshenko (1878-1972)
Eugene Freyssinet (1879-1962)

Hardy Cross (1885-1959)

David Steinman (1887-1960)

Pier Luigi Nervi (1891-1979)

Ulrich Finsterwalder (b. 1897)

Eduardo Torroja (1899-1961)

Anton Tedesko (1903-1994)

Mario Salvadori (1907-1997)

Tung-Yen “T.Y.”' Lin (1912-2003)

Ralph B. Peck (1912-2008)

Henry J. Degenkolb (1913-1989)

Jack R. Janney (b. 1924)

Hannskarl Bandel (1925-1993)

Heinz Isler (b. 1926)

Christian Menn (b. 1927)

Horst Berger (b. 1928)

Charles H. Thornton (b. 1940)

Ray W. Clough (b. 1920)

\section{Subject Proposal}

As a group, decide the topic of your presentation and turn in a single-page proposal for the subject of your report by Monday, September 15. The proposal should identify the engineer who is to be the subject of your report and give a brief overview of his life. Your proposal should also list at least three sources (two of which must be books or journal articles) that you intend to consult in your research. You may not use Wikipedia as a source for your paper, but you may use it to 
locate other primary sources. Only one group will be allowed per individual. I would suggest that you conduct preliminary research to ensure you will have adequate sources. Get started on your research early(!) as you may need to use interlibrary loan for some of your sources.

\section{Demonstration Proposal}

On Monday, October 6 you will turn in a second proposal, which will be for your visual demonstration. This proposal will explain the visual demonstration you anticipate using for your presentation. Your proposal should also briefly explain the structural principle you will be illustrating with the demonstration. See details on the visual demonstration below. Do not start construction of the visual demonstration until you receive confirmation from the instructor that your proposal has been approved.

\section{Report Rough Draft}

The rough draft of the report is due on Thursday, October 16, which will be a writing lab in the class. The rough draft should be an essentially complete paper, as it will be read and critiqued by other students outside your group.

\section{Report Final Draft}

On Friday, October 31 you will turn in a final draft of your report. The work you turn in is expected to be of excellent quality and a large percentage of your grade (see "Grading" below) will be based on this final draft. The intended audience for the report is your structural mechanics classmates.

The report will address each of the areas below in a separate section of the paper.

1. Discuss the technological context of the historical period in which your subject lived and worked. What constituted standard engineering practice of the day? What construction techniques and analytical methods were employed? What construction materials were available? How did this affect the work of your subject?

2. Discuss the socioeconomic and political environments of the day as they relate to your subject's work. What challenges, obstacles, or opportunities did these environments afford?

3. Discuss the education and/or practical training of the subject. How would these compare with those of his contemporary engineers? Discuss your own education in this context.

4. Discuss the personal characteristics of the subject. What were his hobbies, interests, or avocations? Of what importance were these outside activities to the subject's work? What role do such activities play in your current educational environment, or what role do you think such activities will play in your professional engineering life?

The paper should:

- Be eight pages or less and should have at least one figure or table.

- Cite all sources and include a list of references with at least five sources, three of which must be a book or a journal article.

- Follow the style of the American Society of Civil Engineers (ASCE) academic engineering journals (the library has several such as The Journal of Structural Engineering, The Journal of Engineering Mechanics, etc.) in the following ways: 
- Citation of sources and formatting of the list of references. Use the APA citation style in Word 2007, ${ }^{1}$ which is probably the closest to ASCE style.

- Captioning of figures and tables.

- Inclusion of an abstract (150-175 words).

- Note: Use a single column even though the ASCE journals use double columns.

- Follow technical writing standards (see "Effective Engineering Writing" on the course website).

- Use section headings and include introduction and conclusion sections.

- Use 1-1/2 line spacing.

- Be completely free of plagiarism. A good guide for avoiding plagiarism can be found at: http://www.aug.edu/sociology/plagiarism.html

- Include two "important facts" about your engineer that a structural engineer would find particularly interesting. These important facts are not part of the report and should be turned in on a separate piece of paper (handwritten is fine).

You will turn in one copy for the instructor with all group member names. Additional copies, one per group member, will be submitted without any identification of group members. These "anonymous" papers will be distributed to classmates for peer evaluation as described below.

\section{Wikipedia Update}

Based on the information from your report, update the entry (or create a new one) for your subject in the Wikipedia on-line encyclopedia (http://www.wikipedia.org). Add at least four sentences to the article with information on two separate topics. In addition, add at least one reference (web page link or source attribution) to the Wikipedia entry. On the last page of your final draft report give the date you modified Wikipedia and the exact time and IP address (see the history tab).

\section{Peer Critique}

Each of you will be reading one report from another group and critiquing it. Part of your grade for this project will be based on your peer evaluation (see "Grading" below). Your effectiveness as a peer evaluator will be graded by the instructor based on the quality of your feedback. Feedback which is restricted to simply reporting typos and spelling errors will be scored low while feedback that is thoughtful and helps to improve the clarity and quality of the writing will be scored high. Use the "Effective Engineering Writing" summary on the class website as a guide in your critique of the paper you are assigned. The peer reviews will be double blind-reviewers will not know which group submitted the paper and the groups will not know who reviewed their paper.

\section{Group Presentations}

Group presentations will take place on Thursday, November 13. The presentations should:

- Be ten minutes or less,

- Present biographical information about your subject and illustrate the life experiences that influenced the engineer's work,

\footnotetext{
${ }^{1}$ This may require a little bit of customization, such as suppressing the title (hint).
} 
- Give a short overview of the engineering state-of-the-art during your subject's life with examples of how your subject improved engineering practice.

- Clearly reference all images used, including copyright information if applicable. A good source for images is Wikimedia Commons, http://commons.wikimedia.org/.

\section{Visual Demonstration}

Your presentation must also include some type of demonstration, experiment, or other visualization demonstrating a major theoretical or applied contribution of your subject to the field of structural engineering. This visual demonstration should clearly illustrate a structural engineering principle. Don't say, "This technique reduces the structural weight." Instead, explain why the technique works and construct a visual demonstration that illustrates the pertinent engineering principles (talk to the instructor if need be). The visual demonstration will show one application of the principle as it pertains to the subject of your report. Your group will also come up with another example of how the principle would be applied in structural engineering. You will not create a visual demonstration for the second example, simply explain it in your presentation. Note that the visual demonstration should not be mentioned in your written report.

\section{Group Report}

The final paper submissions are due on Friday, November 28. Turn in your final paper, your draft report submittal, and all peer evaluation material. Grading of the final submissions will mainly consist of verifying that the groups used the feedback on the draft report (from both the peer reviewers and the instructor) to improve the paper.

\section{Grading}

Your final grade for the term project will be weighted as follows:

$\begin{array}{ll}\text { Presentation } & 25 \% \\ \text { Visual Demonstration } & 10 \% \\ \text { Draft Report } & 40 \% \\ \text { Final Report } & 15 \% \\ \text { Peer Critiques } & 10 \%\end{array}$

\section{Peer Evaluations}

Scores on the project will be adjusted based on the results from the Comprehensive Assessment of Team Member Effectiveness (CATME):

https://www.catme.org/

\section{Extra Credit}

Extra credit will be granted to group members who prepare a display for Engineering Expo on Thursday, April 3, 2008. Keep in mind that the target audience for Engineering Expo is students in grades 7-12. To earn extra credit, the following must be done:

1. Create supplementary materials explaining your subject. This could be a poster, fact sheet, etc. Be creative and remember your target audience!

2. On Friday, December 12, set up the visual demonstration in the display room (T.B.A.).

3. Turn in a summary sheet to the instructor with the following information:

(a) The names of the group members who helped with the extra credit portion. 
(b) The approximate percentage of work completed by each group member.

(c) A list of group members who will be available to help on the day of Expo (Thursday, April 3, 2008). Note that engineering classes are canceled for Expo and many instructors require students to help out with Expo displays. Also, you do not need to fill out an expo project application. I will be doing this for the entire class.

(d) A suggestion on what to do with any award money received for the display.

The summary sheet is due on Friday, December 12 .

Extra credit will be awarded based on the following:

1. Scoring from the Expo judging rubric. Specifically, the displays will be judged for the "Appearance of display," "Educational content," and "Creativity and originality" entries of the rubric.

2. Reactions from a focus group of students in the target audience.

You can earn up to $10 \%$ extra credit on your final report score.

\section{Acknowledgments}

This report is based on a similar class assignment described by Thurston (1994).

\section{Reference}

Thurston, H. M. (1994) "Influential structural engineers: A project in a third-year structural analysis course," Journal of Engineering Education, 83 (2), 156-160. 


\section{Appendix B: Student Peer Evaluation Form for Written Reports}

Based on your reading of the structural engineer report you were given, answer the following. If the paper did not clearly address the given topics, state as much.

1. Regarding the technological context of the subject, what constituted standard engineering practice of the day? What construction techniques and analytical methods were employed? What construction materials were available? How did this affect the work of the engineer?

2. Regarding the socioeconomic and political environments, what challenges, obstacles, or opportunities did the subject encounter?

3. What was the education and/or practical training of the subject? How would these compare with those of a typical contemporary engineer? What comparison did the authors make to their own education? 
4. What were the hobbies, interests, or avocations of the subject? Of what importance were these outside activities to the subject's work? How did the authors compare these activities to their current educational environment and professional engineering life?

Some of the strengths of the paper are:

Some ways in which the paper could have been improved are:

Give two suggestions on how the paper could be improved based on the suggestions given in "Effective Engineering Writing":

Circle the response that comes closest to your feelings about the following statements.

1. Compared to other technical reports I have read, I enjoyed reading this report.

\section{Completely Somewhat Not really Not at all}

2. This paper represents the best effort of the authors.

\section{Definitely Possibly Not sure Probably not Definitely not}


Appendix C: Student Peer Evaluation Form for Oral Presentations

\section{Subject Engineer:}

1. What life experiences influenced the subject engineer's work?

2. How did the subject engineer improve engineering practice?

3. What was the structural engineering principle illustrated by the visual demonstration?

4. What was the second example (besides the visual demonstration) for the structural engineering principle?

Circle the response that comes closest to your feelings about the following statements.

1. Compared to other technical presentations I have seen, the group was excited to give this presentation.

\section{Definitely Possibly Not sure Probably not Definitely not}

2. The group had practiced their presentation before giving it today.

Definitely Possibly Not sure Probably not Definitely not

3. The visual demonstration was helpful in understanding the structural engineering principle.

Definitely Somewhat Not sure Not Really Definitely not




\section{Appendix D: Instructor Grading Rubric for the Written Report}

- The paper follows citation/reference and captioning style of the ASCE journals +2 Some but not all of the journal style are followed Journal styles do not appear to be followed

- An abstract is included which effectively summarizes the paper +3

The abstract is present but is not a sufficient summary +2

- The paper has a section on the "technological context" of the engineer's work +6 that clearly answers the assigned question(s) from the project assignment

- The paper has a section on the "socioeconomic and political environments" of +6 the engineer's day that clearly answers the assigned question(s)

- The paper has a section on the "education and/or practical training" of the engineer $\quad+6$ that clearly answers the assigned question(s) from the project assignment

- The paper has a section on the "personal characteristics" of the engineer +6 that clearly answers the assigned question(s) from the project assignment

- The paper is eight pages or less (including abstract) +1

- There is at least one figure or table $\quad+2$

- A bibliography is present following a consistent format $\quad+2$ Inconsistencies in the bibliography +1

No bibliography

- The bibliography has at least 5 sources $\quad+1$

- At least three of the sources are from a book or journal $\quad+1$

- Four sentences were added to wikipedia on two different topics +2 A minor addition to wikipedia was made $\quad+1$ No mention of wikipedia in the report $\quad 0$

- A reference was added to wikipedia (web page link or source attribution) +2

\section{TOTAL}

Subtract 1 point for every misspelled word, grammatical mistake, or violation of effective engineering writing (-8 max)

\section{FINAL SCORE}




\section{Appendix E: "Effective Engineering Writing” Student Handout}

To be effective, engineering writing:

- is technically correct;

- is grammatically correct;

- is properly formatted;

- obeys the conventions specific to engineering writing;

- makes it easy for the reader to navigate the document;

- is concise;

- is clear;

- is enjoyable to read.

The bottom line: effective writers make it easy for their audience to read their writing. Effective writers have a good idea of what the reader is thinking, can anticipate questions that arise in the reader's mind, and often ask themselves "how might a reader misinterpret what I am writing?"

\section{GRAMMAR, SPELLING AND PUNCTUATION}

Students are encouraged to refer to a writing guide. The most common mistakes are:

- misuse of semi-colons;

- improper use of commas;

- sentence fragments ;

- run-on sentences;

- ending a sentence with a dangling participle (e.g. "of," "to", etc.);

- beginning a sentence with a conjunction (e.g. "and," "but," "because," etc.)

\section{FORMATTING}

See the ASCE Authors' Guide, for more details on ASCE Journal formatting standards: http://www.pubs.asce.org/authors/index.html

\section{Conventions of EngineEring Writing}

The following conventions of engineering writing must be obeyed when writing your report:

- Avoid using contractions.

- Do not use possessives.

- Write in the third person.

- Do not use clichés ${ }^{1}$ (http://www.westegg.com/cliche/) or vernacular.

- Reference graphics and tables explicitly in the text.

- Reference graphics and tables before they appear in the body of the report.

- Interpret the graphics and tables for the reader.

- Cite references in the report. Include a bibliography that contains only the references that you have cited in the report.

- Use appropriate significant figures throughout the report.

- Always define acronyms and engineering terms that might be unfamiliar to the audience the first time you use them (and only the first time).

- Insert a space between a number and its units.

\footnotetext{
${ }^{1}$ Can you find an example of a cliché in this document?
} 


\section{REPORT NAVIGATION}

Make it easy for the reader to navigate through the report. A table of contents and page numbers are required and are examples of ways to help the reader navigate through the report. Also, do not make the reader continually flip back and forth between the body of the report and the appendix.

An appendix is not a trash can, where you place all of your "extra" information, (e.g. graphics that you were too lazy to insert into the body of the report, tables and tables of data), and through which you expect the reader, like a hungry cat $^{2}$, to enjoy picking through. Pages in the appendix should be numbered, and every page or section in the appendix should be explicitly referenced in the body of the report.

Every paragraph must start with a topic sentence, and every statement in a paragraph must support the topic sentence. Thus, each paragraph should expand upon a single idea. Moreover, a reader should be able to skim through the topic sentences of your report to obtain an overall picture of your report.

\section{CONCISENESS OF WRITING}

Do not be repetitive. Repetitiveness makes reading your report tedious and boring.

Use bulleted lists wisely. A bulleted list can be a very helpful tool. When you find yourself making a list within a sentence, consider placing the list in an indented, bulleted list. On the other hand, do not overuse bulleted lists! Make sure that the items in the list are "parallel." Make sure that you have a lead-in sentence to your bulleted list. (Could this paragraph have been replaced by a bulleted list!?)

\section{Clarity of Writing}

The reader's interpretation of your writing should be the same as your intended meaning. The reader should never ask, "I wonder what they meant to say here?"

Be careful using the word "it" or "this." Make sure that the reader understands what "it" is!

Use the best word possible. Do not use wimpy, vague words, or words that might have multiple meanings.

\section{SUBJECTIVITY OF READER}

Some readers will find your best writing to be excellent; another reader (another supervisor?) may find it unsatisfactory. Get used to it.

\section{ADDitional TiPS}

The following is a list of other tips that you should pay attention to:

- Beware of the word "only."

- Note the location of the period in the sentence above.

- It is a good idea never to start a sentence with the word "it!"

- Be consistent in your capitalization.

- Be consistent in using the same term to refer to the same topic.

- Use a consistent "voice."

- Be consistent in your verb tense.

- Use effective graphics to support your conclusions

- Do not write "see Figure 1 below."

\footnotetext{
${ }^{2}$ This is an example of simile. Avoid using similes in your engineering writing.
} 